\title{
QUAL DEMOCRATIZAÇÃO DO ENSINO SUPERIOR?
}

\author{
François Dubet*
}

\begin{abstract}
Esse artigo, resultante de uma conferência, discute traços do processo de democratização do ensino superior. Procura distinguir analiticamente várias dimensões da democratização, baseadas, por sua vez, em concepções diferentes da justiça: igualdade de oportunidades, meritocracia, utilidades e equidade dos procedimentos. Cada sociedade constrói modelos de democratização desse ensino. A massificação do ensino superior desempenhou papel democrático objetivo, favorável aos grupos sociais antes excluídos. Mas massificação não equivale à democratização. Todas as categorias sociais não se beneficiam da mesma forma da massificação. A democratização do acesso ao ensino superior não depende apenas das famílias. Depende também da estrutura geral do sistema educativo. A meritocracia acadêmica constrói uma hierarquia de competências que é também social, com forte impacto reprodutivo. As desigualdades de utilidade das diferentes formações têm impacto sobre o conjunto das desigualdades sociais. Os sistemas educativos implementam distintos procedimentos de seleção, de concessão de gratuidades, bolsas e auxílios, que podem ser considerados como mais ou menos equitativos segundo as normas de justiça que mobilizam.
\end{abstract}

Palavras-chavE: Ensino superior. Democratização. Valor social dos diplomas. Equidade. Igualdade de oportunidades.

Na maioria dos países, os sistemas de ensino superior se democratizaram. Isso significa simplesmente que estabelecimentos de ensino superior, faculdades e universidades, até então reservados a uma pequena elite social e escolar, abriram suas portas a alunos provenientes de classes sociais mais modestas. $\mathrm{Na}$ América do Norte e em alguns países da Europa, a porcentagem de estudantes no ensino superior é de cerca de $50 \%$ da faixa etária adequada a esse nível, representando o horizonte "da sociedade do conhecimento" traçado pelas agências internacionais como a Organização para Cooperação e Desenvolvimento Econômico - OCDE (Santiago et. al., 2008). Nesse caso, a democratização designaria apenas a abertura de um sistema de ensino e a massificação do acesso a um bem escolar.

\footnotetext{
* École des Hautes Études en Sciences Sociales (EHESS). Centre d'Analyse et Intervention Sociologiques (CADIS). 3ter, place de la Victoire. 33076 Bordeaux.

françois.dubet@u-bordeaux.fr

${ }^{1}$ Este artigo é resultante da conferência apresentada no Seminário Internacional sobre Democratização do Ensino Superior, realizado no PPGSA/UFRJ em novembro de 2013. Tradução de Hermínia Willians Athayde, revisão M. Ligia Barbosa. Por se tratar de uma conferência, as citações e referências são bastante reduzidas, sendo indicados pela editora os trabalhos de referência do autor para os temas específicos
}

A noção de democratização do ensino superior, contudo, pode e deve ser entendida de muitas maneiras diferentes. Para além da simples massificação, é possível falar da democratização do acesso aos estudos superiores, perguntando-se que categorias sociais se beneficiaram da massificação. Outro critério, o da democratização interna, diz respeito às desigualdades internas do ensino superior: os estudantes são mais numerosos, mas acessam níveis muito desiguais nesse sistema. A análise dessas desigualdades internas dos sistemas de ensino superior levanta a questão da democratização como equidade dos procedimentos de seleção, ou, se preferirmos, da democratização como justiça (Dubet, 2004, 2010). Finalmente, é preciso analisar a democratização do ensino superior em termos de utilidades ${ }^{1}$ acadêmicas: qual o valor dos diplomas no mercado de trabalho? Um sistema democrático, sob todos os

1 N.T. A palavra utilizada originalmente em francês foi "Emprise", cuja tradução poderia ser influência, ascendência, utilidade. Esse último termo foi escolhido por se aproximar mais fortemente do significado explicitado pelo próprio autor, de valor. No caso, valor social dos diplomas. Mesmo que essa palavra tenha uma forte conotação econômica, optou-se por "utilidade" por agregar também uma ênfase maior na ideia de valorização, inclusive econômica, que a simples "influência". 
aspectos do conceito, mas no qual os diplomas não valessem nada, não seria realmente democrático (Dubet et al., 2010).

Após ter buscado definir essas diferentes dimensões da democratização escolar, tentaremos mostrar como elas se articulam em diversos sistemas nacionais, comparando, por alto e entre si, alguns países europeus com condições socioeconômicas semelhantes e taxas de massificação próximas. Tudo se passa como se cada sociedade tivesse construído progressivamente seus próprios modelos de democratização do ensino superior.

\section{DEMOCRATIZAÇÃO E MASSIFICAÇÃO}

Sob o pretexto de que a abertura dos sistemas de ensino superior não cumpriu todas as promessas, diversas retóricas conservadoras ou radicais denunciam essa expansão como uma ilusão, quando não como uma catástrofe cultural. Para os conservadores, a massificação teria reduzido o nível cultural das universidades e o teria submetido aos interesses sociais. Para os radicais, ela não alteraria em nada a ordem das desigualdades sociais, exceto por lhe conferir mais legitimidade ainda. As duas avaliações devem ser bastante matizadas.

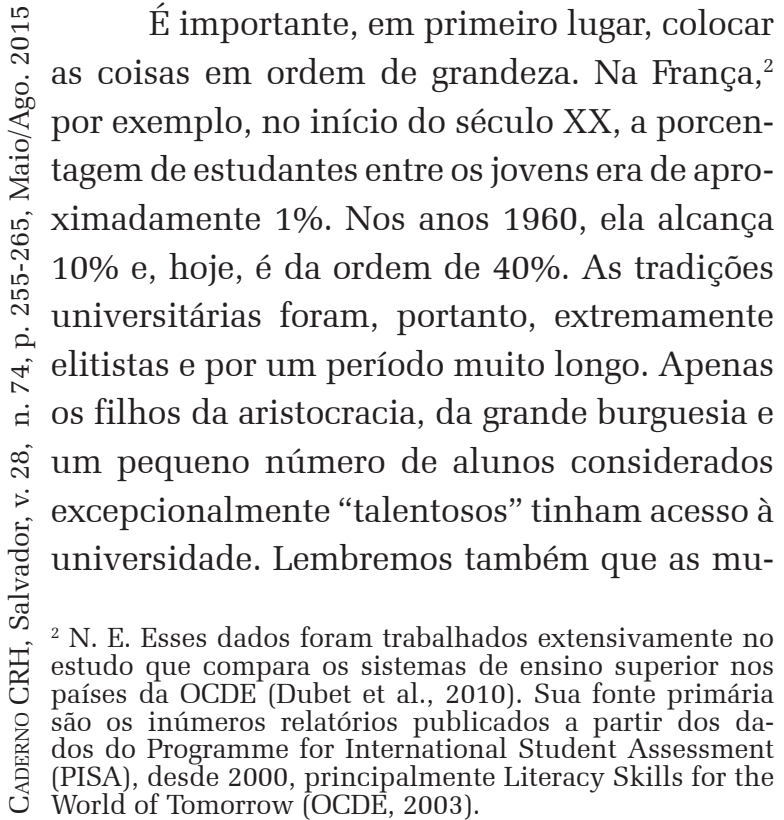

lheres eram excluídas de muitas formações superiores, enquanto hoje em dia elas representam, muitas vezes, a maioria do alunado.

A massificação do ensino superior desempenhou, portanto, um papel democrático objetivo ao aumentar mecanicamente as possibilidades de se fazer estudos longos. As classes médias beneficiaram-se amplamente dessa massificação e uma parte das classes populares também aumentou suas possibilidades de ter acesso à universidade. Mesmo quando se tem prazer em salientar que os filhos de operários têm três vezes menos chances de entrar na universidade do que os filhos de executivos, o fato é que muitos deles entram atualmente, sendo que isso era praticamente impossível há uns cinquenta anos atrás. No fundo, ocorre com o ensino superior o mesmo que ocorre com todos os outros bens: a massificação tem um efeito democrático automático, quer se trate de geladeiras, de automóveis, de televisões ou de diplomas superiores.

Essa democratização foi, portanto, favorável aos grupos que eram praticamente excluídos do ensino superior, mas muitos economistas são de opinião que, além disso, ela foi positiva para a sociedade, por aumentar o capital social da população. Nesse processo, os conhecimentos acadêmicos e as culturas de elite ter-se-iam espalhado pela sociedade, o nível cultural médio da população também teria aumentado, e tudo isso teria tido um efeito muito positivo no desenvolvimento econômico e no enriquecimento da sociedade. Com isso, a massificação universitária teria tido um efeito positivo, inclusive para aqueles que, embora dela não tenham auferido benefícios diretos, se beneficiaram indiretamente: mais médicos, mais engenheiros, mais especialistas, mais profissionais.

Muitos especialistas pensam também que a massificação do ensino superior teria tido um efeito positivo sobre a modernização e a democratização dos valores nas sociedades. De fato, muitas pesquisas demonstram que aqueles que têm diplomas de curso superior aderem 
mais do que os outros a valores progressistas, humanistas e democráticos. Confiam mais na ciência e na democracia e são menos autoritários que os cidadãos com menos escolaridade. De modo geral, desde os anos 1960 e da massificação democrática nos países ricos, os campi e os movimentos estudantis defendem os valores de igualdade, paz, ecologia e democracia: vide a revolta dos campi americanos, o Maio de 68 na França, a revolta da Praça Tiananmen em Pequim, as Primaveras árabes...

Por tudo isso, a maioria dos governos escolheu abrir o acesso ao ensino superior. Muitas vezes, essa noção não é discutida e nos damos conta de que todos os governos, ou quase, jogam essa carta de diversas formas. No entanto, essa confiança na democratização como massificação não basta para fazer a análise de todas as dimensões nela envolvidas.

\section{A DEMOCRATIZAÇÃO DO ACESSO}

Quando se define a democratização com base no critério da igualdade de oportunidades oferecida a todos os indivíduos, de todos os grupos sociais, de ter acesso ao ensino superior, torna-se evidente que a massificação não é necessariamente uma democratização. De fato, sob esse prisma, a democratização exigiria que todas as classes sociais tivessem as mesmas possibilidades e que a população dos estudantes retratasse a sociedade. Ainda que a igualdade de oportunidades de ingressar no ensino superior varie bastante de acordo com os países (é maior na Suécia e no Japão do que na Argentina ou na África do Sul), ela não se concretiza em nenhuma sociedade. Para dizê -lo de forma mais simples, quanto mais elevada a origem social dos indivíduos, mais eles têm oportunidade de cursar o nível superior. Todas as categorias sociais não se beneficiam da mesma forma da massificação. Há cinquenta anos, um número considerável de trabalhos é dedicado a essa questão. A grande maioria destaca três explicações principais para a desi- gualdade de oportunidades. ${ }^{3}$

Os recursos financeiros são um dos principais fatores na desigualdade de acesso à universidade. Não somente alguns países não têm um sistema universitário que não é gratuito e, consequentemente, está fora do alcance das classes sociais mais modestas, mas, mesmo nos países onde os estudos superiores são gratuitos, ou quase, eles têm um custo. Os estudantes precisam viver, alimentar-se e alojar-se durante o período em que estão estudando. Além disso, o tempo dedicado aos estudos representa também uma perda de salário que muitas famílias não podem assumir, uma vez que já esperam dos jovens que se responsabilizem por si mesmos e que contribuam para o sustento da família. Os sistemas de bolsas e de subsídios diversos, as possibilidades de combinar o trabalho com os estudos podem atenuar essa deficiência econômica, mas ela continua a existir assim mesmo. É o que explica porque as classes médias foram as grandes beneficiárias da massificação escolar e porque as classes populares "optam" pelo trabalho precoce ao término dos estudos obrigatórios. Com a crise econômica, observa-se, hoje em dia, a formação de uma categoria de estudantes extremamente pobres. De modo geral, quanto mais uma sociedade é relativamente igualitária, mais o acesso ao ensino superior é democrático.

Contudo, nos países mais ricos relativamente igualitários, as desigualdades econômicas explicam menos as desigualdades de acesso ao ensino superior do que as desigualdades culturais. De fato, o acesso ao ensino superior é condicionado pelo sucesso acadêmico dos alunos no ensino primário e secundário e todos os sociólogos sabem que esse sucesso depende do capital econômico das famílias. Na verdade, até mesmo nos países onde o peso das desigualdades econômicas foi reduzido, as desigualdades dos capitais culturais determinam muito mais as desigualdades escolares. Em alguns casos, há mesmo "resistência" à abertura da universidestacada em Dubet (2010), em especial os capítulos 1 e 3. 
dade por parte das culturas das classes populares, que consideram que esses estudos não são feitos para os filhos de trabalhadores, o que os leva a limitar, elas mesmas, suas ambições. $\mathrm{Na}$ Grã-Bretanha, por exemplo, os filhos da classe operária ingressam menos na universidade do que os filhos de imigrantes, que valorizam muito mais os estudos superiores. Não somente o ingresso na universidade é determinado pelas desigualdades culturais, mas essas desigualdades são mais difíceis de reduzir do que as desigualdades econômicas.

A democratização do acesso ao ensino superior não depende somente dos meios financeiros e dos capitais cultural e acadêmico das famílias. Ela depende também da estrutura geral do sistema educativo. A igualdade de acesso ao ensino superior é mais democrática quando o ensino secundário é amplamente aberto e quando os alunos têm um bom nível e uma relativa igualdade de desempenho. É o que ocorre nos países escandinavos, no Canadá, no Japão e em alguns outros. Em contrapartida, quando o ensino repousa sobre uma base estreita e é muito desigual, o acesso ao ensino superior é muito pouco democrático. Esse foi, por muito tempo, o caso da Alemanha, onde o ensino secundário repousava sobre uma estreita base elitista. É o caso dos países que desenvolveram o seu ensi-

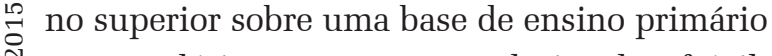
$\stackrel{\sim}{\circ}$ e secundário extremamente desigual e frágil. $\stackrel{8}{\perp}$ Pensamos aqui nos países da África e em alguns đ países da América Latina. Em outras palavras, is a democratização do acesso ao ensino superior Dressupõe que as sociedades já tenham construㄴ.́do um sistema de educação eficaz e relativa+ mente democrático e que não tenham colocado ¿ "o carro na frente dos bois".

\section{A democratização interna}

A observação dos mecanismos de massificação dos sistemas universitários poderia levar a enunciar a seguinte "lei" sociológica: a massificação dos sistemas universitários reduz as desigualdades de acesso, mas acentua as desigualdades internas desses sistemas. Quando os sistemas universitários são malthusianos e relativamente aristocráticos, são também, ao mesmo tempo, relativamente homogêneos, e a distância que separa seus segmentos de maior prestígio dos demais é relativamente curta, porque há pouca concorrência entre eles. De modo inverso, quando os sistemas se abrem, a hierarquia entre os estabelecimentos e entre as universidades não para de aumentar. Decorre daí que, nos sistemas mais abertos, as desigualdades ocorrem menos no momento do ingresso, deslocando-se para dentro do próprio sistema. A relativa igualdade de acesso à universidade é acompanhada de um aumento das desigualdades de acesso aos diversos segmentos do sistema escolar.

Nos sistemas mais abertos, "as verdadeiras" desigualdades são medidas dentro do próprio sistema, e pode-se falar de "democratização segregativa”. Com base em seus recursos financeiros, seu local de residência, suas competências acadêmicas, seu capital cultural, os estudantes se orientam para formações mais ou menos prestigiosas e mais ou menos rentáveis. Por toda a parte, verificam-se profundos afastamentos entre as universidades de maior e de menor prestígio, separando-se, com frequência, as mais antigas das mais novas. Em alguns países, como a França, a principal divisão se encontra entre as grandes écoles e as universidades. Em outros lugares, é na distância entre as universidades públicas e as universidades privadas que se organiza essa hierarquia. Em algumas sociedades, são as universidades públicas as que gozam de maior prestígio; em outras, são as universidades privadas.

É notável como a história universitária de cada país acabou construindo um sistema hierárquico original e, muitas vezes, bastante sutil, que requer que os atores conheçam todos seus mecanismos. Entre os dois polos do sistema, estende-se uma complexa hierarquia baseada na reputação, na capacidade de atrair os melhores estudantes e os melhores profes- 
sores, de garantir a maior utilidade dos diplomas, de construir as redes sociais que fazem com que os antigos estudantes se apoiem mutuamente para monopolizar as posições profissionais de maior prestígio. Na maioria dos países, algumas universidades, algumas escolas e alguns institutos adquiriram um quase monopólio da produção de elites e, geralmente, seus estudantes procedem, eles mesmos, das elites, o que assegura uma forte reprodução social dos dirigentes de empresas, altos funcionários, líderes políticos, e intelectuais.

Hoje, as hierarquias dos estabelecimentos do ensino superior tornaram-se uma questão pública, e a imprensa, as agências governamentais, as classificações internacionais, como a de Shanghai, não param de ranquear os elementos do sistema em termos de prestígio e rentabilidade dos diplomas. Essas hierarquias orientam as estratégias dos estabelecimentos que procuram desenvolver suas vantagens no “mercado" universitário, mas orientam principalmente as escolhas dos estudantes. Quanto mais se reconhece o prestígio de um estabelecimento mais ele pode ser seletivo, ou até mesmo superseletivo, dado que pode jogar, inclusive, com um mercado internacional. Por outro lado, os estabelecimentos menos prestigiosos não podem ser seletivos e, para sobreviver, precisam atrair constantemente novos estudantes.

Essa meritocracia acadêmica, com os melhores estudantes sendo selecionados pelos melhores estabelecimentos e melhores cursos, constrói uma hierarquia de competências acadêmicas extremamente pronunciadas. E, quando se olha de perto, fica evidente que essa hierarquia do mérito acadêmico é também uma hierarquia social, que induz frequentemente uma forte reprodução social, pois, mesmo que um elevado número de estudantes tenha acesso ao ensino superior, a distribuição deles no sistema continuará a ser extremamente desigual.

\section{DEMOCRATIZAÇÃO DAS UTILIDA- DES DOS DIPLOMAS}

Em geral, a democratização dos sistemas universitários é analisada a montante, ou seja, a partir das "entradas" desses sistemas: tentase medir os efeitos das desigualdades sociais sobre as desigualdades acadêmicas. Mas essa abordagem está longe de ser suficiente, porque o ensino superior distribui bens acadêmicos, diplomas, cujas utilidades dependem das relações existentes entre a produção de diplomas e a de empregos que exigem maiores qualificações. Podem-se considerar, como desigualdade fundamental, as desigualdades de utilidade das qualificações acadêmicas. ${ }^{4}$

Quando os sistemas de ensino superior eram malthusianos e reservados a uma elite restrita, a utilidade social dos diplomas podia ser garantida por sua escassez. A situação ainda era favorável nos anos 1960 na Europa, quando a massificação escolar era menos rápida que a demanda de empregos que requeriam maiores qualificações; nesse caso, os diplomas do ensino superior podiam se multiplicar e ter, ao mesmo tempo, um valor crescente no mercado de trabalho. Hoje, nos países que já massificaram há algum tempo o seu ensino superior, a situação já não é bem a mesma. Em toda parte, os diplomas do ensino superior desempenham um papel útil no acesso ao emprego e no nível da renda, mas esse papel mesmo tornou-se extremamente desigual.

No topo da hierarquia, as formações mais seletivas têm uma espécie de monopólio sobre o acesso às profissões e às diversas elites que, muitas vezes, saem das mesmas escolas e das mesmas universidades. À custa de uma forte seleção e de sólidas redes, essas formações mantêm uma utilidade muito grande dos diplomas relacionados a "rendas" acadêmicas. Aqui, a correlação entre diplomas e empregos ${ }^{4}$ N. E. Essa discussão é feita de maneira bastante alentada em Dubet et al. (2010). Em português, podemos encontrar algumas indicações em Dubet et al. (2012). Nesse último artigo, com excelente tradução, utilizou-se a palavra "influência” para traduzir a ideia de "emprese". 
continua forte. Todavia, quanto mais "se desce" na hierarquia do sistema e mais se aproxima de formações gerais pouco seletivas, mais a correlação se enfraquece e menos os mercados de trabalho reconhecem as formações escolares pouco seletivas e pouco especializadas. Os estudantes precisam, então, fazer o esforço de se "inserir", ou seja, transformar suas competências acadêmicas em competências profissionais.

Às vezes, essa perda relativa de valor dos diplomas é vivida pelos envolvidos como um processo subjetivo de perda de status social. Os estudantes cursaram muito mais estudos superiores do que os seus pais para ocupar, ao término de seu percurso, posições profissionais e sociais próximas das que eles tiveram. Muitas vezes, esses estudantes se sentem traídos pela universidade que lhes "vendeu" uma esperança de mobilidade social que ela não lhes ofereceu. Com a multiplicação das formações universitárias, é preciso pagar cada vez mais para alcançar a mesma posição social. Certos analistas falam disso como "over education", designando, assim, uma ruptura da relação entre o mercado dos diplomas e o do trabalho. ${ }^{5}$ A essa "inflação" de diplomas é preciso acrescentar a redução da correlação entre as formações ou cursos e os empregos. Isso ocorre quando uma porcentagem muito $\stackrel{2}{5}$ alta de estudantes - na França, a proporção é de sem relação com sua formação. ${ }^{6}$

Um dos efeitos induzidos pela massificação do ensino superior é a deterioração da situação da população que não possui diploma. Quando os diplomas eram raros, sua ausência † não era um estigma, o que não é mais o caso $\dot{a}$ hoje, quando as taxas de escolarização aumen$\stackrel{\infty}{\sim}$ tam a ponto de alcançar, como é o caso na Fran-

${ }^{5}$ N. E. Esse tema é clássico na sociologia da educação francesa. Entre os estudos do autor, pode-se tomar como referência Dubet 2004 e 2010.

I ${ }^{6}$ N. E. Todos os dados sobre o ensino superior francês e, em geral, todas as estatísticas da população francesa estão 8 disponíveis no site do Institut National de la Statistique et des Études Économiques (INSEE). Em particular, os dados sobre o sistema de ensino podem ser encontrados em http://www.insee.fr/fr/themes/theme.asp?theme=7. ça, mais de 70\% dos possuidores de diploma de educação secundária. Nesse caso, aqueles que não são diplomados se veem condenados ao desemprego, à precariedade e à marginalidade profissional. Basicamente, a massificação escolar exclui violentamente aqueles que não tiraram proveito dela.

As desigualdades de utilidade das formações universitárias participam, portanto, das desigualdades: quanto mais elas são desiguais, mais aumenta o impacto das desigualdades educacionais propriamente ditas. É possível demonstrar, assim, que a influência dos diplomas sobre o acesso ao emprego e sobre o salário aumenta as desigualdades educacionais e a sua reprodução. Os sistemas nos quais os diplomas têm um valor menor podem ter desigualdades educacionais relativamente mais fortes, mas o impacto sobre as desigualdades sociais que delas decorre é mais fraco ${ }^{7}$. Não se deve, portanto, ignorar as desigualdades dos outputs ou da situação à jusante das formações para apreender todas as dimensões das desigualdades.

\section{DEMOCRATIZAÇÃO E EQUIDADE}

O mecanismo geral que acabamos de descrever não funciona de forma automática, porque cada sistema educativo implementa procedimentos de escolha e de seleção que podem ser considerados como mais ou menos equitativos do ponto de vista das normas de justiça que mobilizam. Afinal, é provável que um sistema puramente meritocrático e gratuito não impeça a reprodução das desigualdades no ensino superior e, mesmo assim, possa ser considerado ${ }^{7}$ N. E. Essa ideia, que pode parecer contraditória, constitui um dos pilares importantes do trabalho de Dubet et al, 2010. Indica, na verdade, a complexidade das relações que se estabelecem entre o sistema de ensino e a organização das hierarquias sociais. O que o argumento de François Dubet mostra é que essas relações não são lineares. Ao contrário, naquelas sociedades que consideraríamos mais democráticas, justamente por serem mais abertas ao mérito medido como escolarização, podemos encontrar um sistema escolar mais fechado, mais competitivo, mais hierarquizado. Assim, fica claro porque, numa sociedade que dá pouco valor à escolarização ou aos diplomas, as desigualdades escolares, por maiores que sejam, não constituem um fator muito forte de produção de desigualdades sociais. Ver também, sobre essa questão, Duru-Bellat, 2009. 
formalmente justo e equitativo. No que tange a isso, parece que os sistemas de ensino superior combinam critérios de justiça diferentes.

Um desses critérios é a questão da gratuidade dos estudos. A priori, os sistemas nos quais os estudantes pagam apenas taxas reduzidas de matrícula são nitidamente mais equitativos do que os que exigem uma elevada contribuição financeira dos estudantes. No primeiro caso, o peso das desigualdades econômicas é neutralizado de forma global. Mas as desigualdades culturais e os desempenhos acadêmicos dos estudantes continuam exercendo seus papéis nos sistemas gratuitos. E, se os melhores estudantes que ingressam nas melhores universidades gratuitas são procedentes das categorias sociais mais favorecidas, seus estudos são pagos pelo conjunto dos contribuintes, dentre os quais todos aqueles cujos filhos não estudam nessas instituições. É o que ocorre em certos países, como o Brasil e a França, onde as formações de maior prestígio são, ao mesmo tempo, gratuitas e, na realidade, reservadas às elites acadêmicas e sociais. Também não é incomum que os estudos de menor prestígio feitos por estudantes de meios mais modestos sejam pagos. Nesse caso, a gratuidade é um presente dado aos ricos. Para decidir sobre a equidade do financiamento dos estudos superiores é, portanto, importante avaliar, caso a caso, quem financia os estudos e quem se beneficia deles. Sem esse cálculo, nada indica que a gratuidade seja sempre mais equitativa que o pagamento de uma parte do custo total dos estudos pelos próprios estudantes.

O mesmo tipo de dilema de justiça surge em relação aos sistemas de bolsas e auxílios dados aos estudantes em função dos seus recursos econômicos e de seus sucessos acadêmicos. É mais justo beneficiar, de forma mais reduzida, muitos estudantes, como é o caso na França, ou ajudar muito os que realmente o merecem? Os estudantes beneficiados por bolsas ou outras formas de auxílio devem poder escolher livremente seus estudos, ou devem ser orientados para campos de formação considerados necessários pela sociedade? É provável que os sistemas mais justos sejam os que outorgam as bolsas com base numa combinação de critérios econômicos e de mérito acadêmico. Há ainda a questão dos empréstimos garantidos que existem no Canadá, nos Estados Unidos ou na Grã-Bretanha. Esses sistemas podem ser considerados justos desde que o mercado de trabalho absorva rapidamente os estudantes que se beneficiaram da utilidade das formações superiores.

Os procedimentos de seleção também podem ser questionados quanto à justiça. Seria mais justo selecionar os estudantes no início de seus estudos superiores, garantindo-lhes que prosseguirão até o término, ou seria mais justo abrir as portas da universidade e selecioná-los ao longo de seus percursos acadêmicos? A primeira escolha não é muito equitativa, porque se sabe que ela favorece os estudantes mais privilegiados, que estão mais aptos a passar nesses exames e a se beneficiar de um preparo específico. Mas a segunda solução pode também não ser mais justa e mais democrática, pois se sabe que os estudantes que não lograrem concluir o curso terão perdido muitos anos e feito sacrifícios muitas vezes desnecessários. Na França, em certas formações universitárias, um em cada dois estudantes abandona os estudos durante o curso. Além disso, ao longo dos anos, são os estudantes menos privilegiados que o fazem. Podemos, então, indagar sobre qual seria a escolha menos iníqua.

É mais justo favorecer o acesso de alguns estudantes de origem modesta às formações de elite, ou será melhor orientá-los para carreiras menos ambiciosas, mas que correspondam melhor às suas "necessidades"? No primeiro caso, parece óbvio que a igualdade de oportunidades é mais valorizada, mas, em contrapartida, muito poucos estudantes poderão se beneficiar disso. No segundo caso, as desigualdades entre as carreiras não se reduzem, porém os estudantes podem ter mais possibilidades de sucesso. A França parece ter preferido o primeiro modelo, e a Alemanha, o segundo. Qual é o mais justo ou, melhor, o menos injusto? 
As políticas de discriminação positiva que introduzem quotas para mulheres e (ou) para membros de minorias culturais por muito tempo discriminadas também levantam dilemas de justiça que são difíceis de julgar. Por um lado, compensam injustiças históricas instauradas em nome da igualdade social, tendo, assim, o mérito de reconhecer que o jogo normal da competição acadêmica exclui grupos culturais e sociais e que é preciso, portanto, iniciar um movimento voluntário de democratização. Por outro lado, essas políticas prejudicam a igualdade de oportunidades e podem ser sentidas como negação de justiça pelos membros da maioria e como humilhação por parte de membros de minorias que delas se beneficiam por verem o seu mérito questionado. É por isso que, na maior parte do tempo, nega-se a prática dessas políticas e elas são implementadas com cuidados.

Ainda que pareça óbvia a existência de políticas mais justas que outras, é preciso enfatizar que todas as normas de equidade se voltam facilmente contra si mesmas. Daí a importância de observar, de perto, sua implementação para julgá-las. Deve-se também ter em conta que a educação constitui sempre um investimento público e individual que traz benefícios coletivos e individuais e que a escolha entre os dois tipos de custos e benefícios : 20 é uma dimensão essencial da equidade. Os $\stackrel{\sim}{\circ}$ estudantes formados devolvem à sociedade o que dela receberam em termos de qualificação, ou apenas angariam benefícios pessoais? Podese oferecer uma formação gratuita aos futuros traders ou aos médicos que se dedicam à cirurgia estética nos bairros chiques, quando faltam - médicos nos bairros pobres?

\section{MODELOS EUROPEUS DE SISTE-} MAS DE ENSINO SUPERIOR

Os processos, os mecanismos e as questões gerais da democratização do ensino superior que acabamos de mostrar não obliteram as peculiaridades nacionais. Na verdade, cada sistema constrói seus próprios modelos, implanta seus próprios valores e se defronta com suas próprias contradições. Evocaremos três sistemas europeus que, de certa forma, apresentam uma forte coerência interna. É evidente que esse ângulo de análise é extremamente estreito e que a pesquisa requereria comparações muito mais amplas.

\section{O elitismo republicano francês}

O modelo escolar francês se quer igualitário e meritocrático. ${ }^{8}$ Igualitário, pois permaneceria muito ligado à gratuidade dos estudos e aos diplomas nacionais, ainda que essa exigência seja difícil de manter com a multiplicação das formações pagas e o crescimento do número de estudantes pobres. Meritocrático, pois esse sistema funcionaria baseado na segmentação entre as grandes écoles, muito elitistas, e as universidades, que acolhem o restante dos estudantes; em todos os casos, os estudantes são orientados apenas com base em seu desempenho acadêmico. Na verdade, o modelo funciona baseado no ideal do "elitismo para todos" e, para atenuar o peso da reprodução social, instauram-se sistemas de formação reservados aos alunos de condições modestas, mas talentosos e merecedores, para que ascendam à elite. Contudo, são muito poucos os que conseguem trilhar esses percursos. Ao mesmo tempo, o ensino superior francês repousa sobre um ideal "adequacionista", segundo o qual cada diploma deve conduzir a um emprego ou a um nível de emprego específico. Evidentemente, essa adequação só funciona para segmentos seletivos do sistema, que recompensam apenas os estudantes que são muito bons, aqueles cujo percurso acadêmico é perfeito.

O modelo universitário extremamente meritocrático e elitista, tal como o da Coreia e o do Japão, explica por que os estudantes são profundamente pessimistas e estressados: eles

${ }^{8}$ N. E. Além das obras do próprio François Dubet sobre o funcionamento do sistema de ensino francês, esse tema também foi tratado recentemente por Baudelot e Establet (2009). 
temem não ter um percurso acadêmico perfeito e ter-se orientado mal, sabendo que é muito difícil mudar de direção. Ao mesmo tempo, os estudantes também reconhecem que esse sistema lhes oferece certa segurança e, em geral, se opõem a reformas que consideram arriscadas.

\section{O liberalismo britânico}

Esse sistema repousa sobre as escolhas individuais. Os estudantes escolhem seus estudos em função de suas competências acadêmicas, de seus recursos econômicos e de seus projetos pessoais. São menos auxiliados por bolsas do que por financiamento, já que, no modelo liberal, as formações universitárias são investimentos que devem trazer um retorno para os indivíduos. Enquanto os estudantes franceses são encaminhados para formações específicas rígidas, os estudantes britânicos podem definir seu currículo de modo mais pessoal, escolhendo as formações para construir um curriculum vitae mais pessoal.

É com base nesse currículo que os jovens ingleses se apresentam no mercado de trabalho, onde o diploma conta menos que o perfil pessoal do candidato. Assim, os dispositivos de auxílio aos estudantes desfavorecidos focam mais nos projetos dos estudantes, não se restringindo apenas a suas competências acadêmicas. Em última análise, o sistema britânico produz e reproduz tantas desigualdades quanto o francês, mas o faz de forma distinta. Os estudantes ingleses são muito mais otimistas e confiantes em si mesmos que os estudantes franceses, e seus protestos se dirigem principalmente ao preço dos estudos e ao sistema de empréstimos bancários, especialmente quando o desemprego desperta neles o medo de não poder pagar.

\section{A "bildung" sueca}

Esse é um sistema cuja marca repousa sobre a igualdade e a liberdade de se construir a si mesmo durante os estudos. O sistema universitário é pouco hierarquizado, e a cada estudante se oferece a possibilidade de ter seis anos de estudo, que podem ser cursados entre os 18 e os 54 anos, com base no modelo da formação ao longo de toda a vida. Trata-se de oferecer aos estudantes tempo para escolher e combinar, da melhor forma possível, os estudos e o trabalho assalariado. Quase 50\% dos estudantes suecos são assalariados ou vêm do mundo do trabalho para se formar.

Esse sistema, embora possa parecer mais justo, funciona numa sociedade profundamente igualitária, em que o mérito conta menos do que na França ou na Grã-Bretanha. Ele funciona também num Estado do bem-estar social eficaz e generoso, cuja continuação nessas condições é incerta no futuro. Ao mesmo tempo, esse modelo, tanto quanto o britânico, é individualista, pois importa dar às pessoas o tempo de se formarem e saberem o que querem. Os estudantes suecos são, em geral, otimistas e confiantes em si mesmos, ainda que o padrão de igualdade seja às vezes vivido como uma forma de conformismo. Ao mesmo tempo, formações mais elitistas são criadas para colocar a Suécia no "mercado" da competição universitária internacional.

\section{REFLEXÕES FINAIS}

Parece possível distinguir, analiticamente, várias dimensões da democratização escolar, baseadas, por sua vez, em concepções diferentes da justiça: igualdade de oportunidades, meritocracia, utilidades e equidade dos procedimentos. Embora não seja difícil distinguir esses modelos, mostrar como eles se estruturam é mais complicado, porque, na maioria das vezes, são relativamente contraditórios entre si; o que se ganha em um critério de democratização pode se perder num outro. Os efeitos paradoxais da massificação dos sistemas de ensino superior deveriam nos levar a questionar a crença unânime em seus benefí- 
cios. Ao que parece, a qualidade da formação escolar básica - aquela compreendida desde a infância ao final do ensino médio - é um fator bem mais decisivo na qualidade da educação, pois pode ser comum a todos os membros de uma sociedade e porque influencia a personalidade e os valores muito mais claramente que a formação superior considerada isoladamente. É também naquele nível do ensino que os sistemas escolares têm mais liberdade para agir sobre as relações existentes entre a amplitude das desigualdades sociais e a das desigualdades escolares, dado que sabemos que sociedades comparáveis em nível global produzem desigualdades escolares de amplitude distinta.

Recebido para publicação em 12 de janeiro de 2015

Aceito em 15 de março de 2015

\section{REFERÊNCIAS}

BAUDELOT, C.;ESTABLET, R. L'élitisme républicain:l'école française à l'épreuve des comparaisons internationales. Paris: Éditions du Seuil, col. La république des idées, 2009. $117 \mathrm{p}$.

DUBET, François. L'école des chances: qu'est-ce qu'une école juste? Paris: Seuil, 2004. 96 p.

. Les places et les chances. Paris: Seuil, 2010.122 p.

; DURU-BELLAT, Marie; VÉRÉTOUT, Antoine. Les Sociétés et leur école: emprise du diplôme et cohésion sociale. Paris: Seuil, 2010. 224 p.

As desigualdades escolares antes e depois da escola: organização escolar e influência dos diplomas. Sociologias, Porto Alegre, v. 14, n. 29, p. 22-70, 2012.

DURU-BELLAT, Marie. Le mérite contre la justice. Paris: Les Presses de Sciences Po. (Nouveaux débats), 2009. $166 \mathrm{p}$.

OCDE. Literacy skills for the world of tomorrow. Further Results from PISA 2000. Executive Summary. Paris: OCDE, 2003. Disponível em: http://www.oecd.org/edu/ school/2960581.pdf.

SANTIAGO, P.; TREMBLAY, K; BASRI, E.; ARNAL, E. Tertiary education for the knowledge society. Special Features: equity, innovation, labour market, internationalization. v. 2, OECD, 2008. Disponível em: <http://www.oecd.org/education/skills-beyond-school/ 41266759.pdf >. ISBN 978-92-64-04652-8. 


\section{WHAT DEMOCRATIZATION OF HIGHER EDUCATION}

\author{
François Dubet
}

This article discusses features of higher education democratization process. It seeks to distinguish analytically various dimensions of democratization, based in turn on different conceptions of justice: equality of opportunity, meritocracy, utilities and fairness of procedures. Each society constructs models of democratization of education. The massification of higher education played democratic role, favorable to social groups previously excluded. But massification is not equivalent to democratization. All social categories do not benefit in the same way from it. The democratization of access to higher education depends not only on the families. It also depends on the overall structure of the education system. The academic meritocracy builds a hierarchy of skills that is also social with strong reproductive impact. Utility inequalities of different courses have an impact on all the social inequalities. Educational systems implement different selection procedures, provide gratuities, grants, scholarships, which can be considered as more or less equitable according to the norms of justice that they mobilize.

KEY wORDS: Higher education. Democratization. Mots-Clés: Enseignement supérieur. Démocratisation. Influence of diplomas. Equity. Equality of oppor- Emprise des diplômes. Équité. Égalité de chances. tunities.

\section{QUELLES DEMOCRATISATIONS DE L'ENSEIGNEMENT SUPERIEUR?}

\author{
François Dubet
}

Cet article analyse quelques traits du processus de démocratisation de l'éducation. Il cherche à établir une distinction analytique entre les différentes dimensions de la démocratisation, basée à son tour sur les différentes conceptions de la justice: égalité des chances, la méritocratie, l'emprise des diplômes et l'équité des procédures. Chaque société construit ses propres modèles de démocratisation de l'éducation. La massification de l'enseignement supérieur a joué un rôle démocratique, favorable aux groupes sociaux précédemment exclus. Mais massification "n'st pas équivalente à la démocratisation. Toutes les catégories sociales n'en bénéficient pas de la même manière. La démocratisation de l'accès à l'enseignement supérieur ne dépend pas seulement des familles. Elle dépend aussi de la structure globale du système éducatif. La méritocratie scolaire construit une hiérarchie des compétences qui est aussi sociale, avec un impact important sur la reproduction sociale. Les emprises inégales des diplômes de différents cours ont un impact sur toutes les inégalités sociales. Les systèmes éducatifs établissent des procédures de sélection différentes, fournissent les subventions, les bourses, qui peuvent être considérées comme plus ou moins équitable selon les normes de la justice qu'ils mobilisent. 
